\title{
EXPLORANDO EL IMPACTO PSICOLÓGICO DEL PROCESO DE DEPORTACIÓN EN INMIGRANTES MEXICANOS d。
}

\author{
Anna López ${ }^{\text {a1}}{ }^{(D)}$, Ivelisse Torres Fernández ${ }^{b}{ }^{\circledR}$, Jessica Rodríguez ${ }^{a}{ }^{\circledR}$, \\ Jesús Cisneros ${ }^{\mathrm{C}} \mathbb{\mathrm { D }}, \boldsymbol{\&}$ Juventino Castro ${ }^{\mathrm{a}} \mathbb{D}^{2}$
}

\author{
New Mexico State University, Las Cruces, United States of America a; \\ Universidad Albizu, San Juan, Puerto Rico ${ }^{\text {b }}$ University of Texas, El Paso, \\ United States of America ${ }^{\mathrm{c}}$.
}

\begin{abstract}
RESUMEN
El propósito de este estudio cualitativo es explorar el impacto psicológico del proceso de deportación en inmigrantes mexicanos. Este estudio utilizo un enfoque fenomenológico para analizar las entrevistas realizadas a 10 individuos que fueron deportados de los Estados Unidos. El análisis de datos reveló la presencia de tres categorías principales: El Trauma de la Deportación, Volver a Empezar, y Las Cicatrices Emocionales. La primera categoría principal, El Trauma de la Deportación, se dividió en dos subcategorías: El miedo a lo desconocido y El sentirse vulnerable. La segunda categoría principal, Volver a Empezar, se dividió en tres subcategorías: El sentirse fracasado, Adaptarse a una nueva vida, y Los sueños no realizados. La última categoría principal, Las Cicatrices Emocionales se dividió en dos subcategorías: Depresión y Tristeza. Implicaciones, limitaciones, y sugerencias para investigaciones futuras también son presentadas.
\end{abstract}

Palabras Claves

deportación; impacto psicológico; salud mental

\section{AbSTRACT}

The purpose of this qualitative study is to explore the psychological impact of the deportation process on Mexican immigrants. This study used a phenomenological approach to analyze interviews with 10 individuals who were deported from the United States. Data analysis revealed the presence of three main categories: Deportation Trauma, Starting Over, and Emotional Scars. The first main category, The Trauma of Deportation, was divided into two sub-categories: Fear of the unknown and Feeling vulnerable. The second main category, Starting Over, was divided into three sub-categories: Feeling like a failure, Adjusting to a new life, and Unrealized dreams. The last main category, Emotional Scars, was divided into two subcategories: Depression and Sadness. Implications, limitations, and suggestions for future research are also presented.

Keywords

deportation; psychological impact; mental health

\footnotetext{
${ }^{1}$ Correspondence about this article should be addressed to Anna López: annalo@nmsu.edu

${ }^{2}$ Los autores agradecen y expresan su reconocimiento a la licenciada Patricia Valencia y en especial a las personas entrevistadas que compartieron sus experiencias.
} 


\section{EXPLORING THE PSYCHOLOGICAL IMPACT OF THE DEPORTATION PROCESS ON MEXICAN IMMIGRANTS}

\section{Introducción}

La deportación de personas que han nacido fuera de los Estados Unidos y que no cuentan con un estatus migratorio que les permita vivir de acuerdo a las leyes de inmigración de los Estados Unidos, representa una situación con repercusiones en diversos aspectos de la vida política, económica, y social (Brotherton \& Barrios, 2011; Kanstroom,2012). Tales repercusiones se hacen evidentes tanto en el ciudadano común, como en las agendas políticas de los gobernantes de los Estados Unidos, y de los países de orígenes de los inmigrantes. Este tema se ha convertido en una problemática en la que todos plantean medidas para intentar solucionar los dilemas que produce este fenómeno, pero que, por la evidencia de las condiciones de vida de los inmigrantes indocumentados en los Estados Unidos, aún no se han implementado acciones en beneficio de este grupo, quienes junto con sus familias son los principales afectados.

Los peligros a los que se enfrentan quienes viajan desde los lugares más remotos del centro y el sur del continente americano con la intención de cruzar la frontera hacia los Estados Unidos, solo se pueden explicar al escuchar de voz de los inmigrantes las condiciones de pobreza, la desigualdad social, los niveles de delincuencia, y en general, la falta de oportunidades existentes en sus países de origen (ej., APA, 2012; Asakura \& Torres Falcón, 2013). Uno de los puntos de cruce más utilizados por quienes intentan llegar a los Estados Unidos se encuentra en el desierto de Arizona. Este punto es conocido como "la carretera del diablo" debido a su peligrosidad y frecuencia con la que se pueden encontrar cadáveres de inmigrantes (Aguirre \& Simmers, 2008).

En los mensajes emitidos por los medios de comunicación norteamericanos, así como en el lenguaje político y en las opiniones de la ciudadanía en general, el tema de la inmigración y la deportación de ciudadanos extranjeros parecen agruparse en dos vertientes principales. Por una parte, se puede distinguir entre quienes buscan una reforma migratoria que permita regularizar el estatus legal de los inmigrantes que viven en los Estados Unidos, y cuya postura se basa principalmente en las potenciales violaciones a los derechos humanos que serían objeto los inmigrantes enfrentando un nuevo periodo de deportaciones masivas (Hernández, 2010). Por otro lado, también se pueden identificar las ideas de quienes buscan a toda costa la deportación masiva de todo inmigrante indocumentado (Menjívar \& Abrego, 2012). Cabe señalar que, en la actualidad, dichas 
posturas han cobrado auge debido a las nuevas políticas migratorias y el recrudecimiento de las deportaciones en la frontera México-Estados Unidos (U.S. Department of Homeland Security, 2017; U.S. Immigration and Customs Enforcement, 2017). Las actuales campañas políticas parecen estar basadas más en las agendas de los partidos políticos que en las necesidades particulares de los de los inmigrantes y sus familias.

De lo anterior se desprende la necesidad de desarrollar investigaciones que permitan el acercamiento y sensibilización ante la realidad que viven en el día a día la población de inmigrantes indocumentados en los Estados Unidos, particularmente con respecto a lo que ocurre luego de una deportación. Pero también en lo que se refiere al trato recibido por los agentes de inmigración que intervinieron en su deportación, ya que como mencionan Aranda y Vaquera (2011), muchos de los afectados mencionan haberse sentido señalados, tratados injustamente, y haber sido víctimas de micro y macro agresiones por su condición de inmigrantes y por su aspecto físico.

A pesar de que existe una gran cantidad de estudios acerca del impacto psicológico de la inmigración en la literatura especializada en salud mental (ej., Achotegui, 2009; Alvarado, 2008; Casas, 2014; Hipólito-Delgado \& Mann, 2012; Kirmayer et al., 2011; Torres et al., 2011), este manuscrito pretende aportar al vacío existente en las narrativas de individuos que han sufrido la experiencia de una deportación. Este manuscrito también tiene como propósito presentar el impacto emocional y carencias que sufren los inmigrantes y sus familias cuando son deportados (ej., Bojórquez et al., 2015; Brabeck et al., 2014; Dreby, 2012; Hagan et al., 2011), y presentar el aspecto humano que las estadísticas tienden a omitir.

La importancia y relevancia de este estudio proviene de la escasez de información sobre las experiencias personales posteriores a una deportación de los inmigrantes en los Estados Unidos (López, 2012), y que a su vez contribuye a la falta de información y sensibilización para los profesionales que intervienen en este proceso, ya sean abogados, legisladores, profesionales de la salud mental, o agentes de la patrulla fronteriza.

Por lo tanto, este manuscrito intenta contribuir al conocimiento de quienes intervienen en el proceso de deportación de un individuo, y de los profesionales de la salud mental que atienden las necesidades de esta población y sus familias. Mediante la exploración de estas narrativas, este estudio examina los efectos psicológicos y emocionales que provoca el fenómeno de la deportación tanto a nivel personal como familiar. 


\section{Método}

\section{Diseño de la Investigación}

Para la realización de esta investigación fue utilizado el método fenomenológico. Los participantes fueron entrevistados con la intención de obtener un mejor entendimiento de las experiencias relacionadas con su deportación de los Estados Unidos. Como es mencionado por Creswell (2013), el uso de este método proporciona a los investigadores la oportunidad de obtener un mejor entendimiento sobre las experiencias de los participantes.

\section{Procedimientos}

Cada participante tomó parte en una entrevista semiestructurada. Debido a que todos los participantes residían en México al momento de las entrevistas, estas fueron realizadas vía telefónica. Asimismo, las entrevistas fueron grabadas con la intención de generar transcripciones para facilitar el análisis de datos. Cada entrevista duró de 45 minutos a una hora y media, aproximadamente. Todos los participantes fueron entrevistados en español. El enfoque principal de la entrevista fue entender cuáles han sido las experiencias de los participantes en relación con su proceso de deportación.

\section{Instrumentos}

Los instrumentos utilizados para esta investigación incluyeron el consentimiento informado, información socio-demográfica, y la guía de preguntas para la entrevista semiestructurada. En lo referente al consentimiento informado para la participación en esta investigación, los investigadores solicitaron una excepción para solamente requerir que los participantes ofrecieran un consentimiento verbal en sustitución de un consentimiento por escrito. Esta decisión fue tomada debido a la posible vulnerabilidad de los participantes y para poder mantener el mayor estándar de confidencialidad posible para ellos. Toda la información y los instrumentos relacionados con esta investigación estuvieron disponibles en inglés y español. 


\section{Participantes}

Los participantes fueron reclutados utilizando el método de muestreo de bola de nieve. Un informante clave fue solicitado para ayudar a identificar a los posibles participantes y para difundir la información relacionada con esta investigación. Todos los participantes fueron recompensados con \$20 USD por su participación sin la obligación de terminar la entrevista y con la opción de retirarse en cualquier momento. En cuanto a la elegibilidad para la participación en esta investigación se incluía: (a) ser mayor de 18 años; (b) haber sido deportado/removido de los Estados Unidos hace menos de dos años en el momento de dar la entrevista; y (c) residir en México en el momento de la entrevista. Con el propósito de proteger la privacidad y confidencialidad de los participantes, los investigadores nunca recogieron los verdaderos nombres o información de contacto de ninguno de los participantes. Por lo tanto, los participantes escogieron un pseudónimo el cual fue utilizado para presentar los resultados.

Un total de 10 participantes fueron incluidos en esta investigación, tres mujeres y siete hombres con un rango de edades de entre 25 a 62 años. Todos los participantes reportaron que su actual residencia estaba localizada en México, en particular, ciudades fronterizas con los Estados Unidos. Con excepción de dos participantes, todos los participantes reportaron tener al menos un hijo/a. Dos de los participantes indicaron tener al menos un hijo/a que permanecía en los Estados Unidos al momento de la entrevista. Nueve de los diez participantes reportaron estar empleados, cuatro de ellos indicaron tener trabajos gubernamentales (i.e., bombero, secretario/a). Los demás participantes indicaron trabajar en escuelas, maquiladoras, ranchos, o limpiando casas.

Solo dos de los diez participantes indicaron haber sido detenidos y deportados debido a un intento fallido de cruzar la frontera. Siete de los diez participantes fueron detenidos mientras residían en los Estados Unidos. Uno de los participantes compartió que había sido detenido después de intentar renovar su visa en uno de los puertos de entrada. Solamente uno de los diez participantes reportó haber sido detenido en la frontera y nunca haber llegado a los Estados Unidos. Para los demás participantes, el tiempo de residencia en los Estados Unidos fue de 2 meses a 5 años. A continuación, se describe brevemente las historias de los diez participantes.

\section{Ramón}

A la edad de 25 años, Ramón, decidió quedarse en los Estados Unidos después de un viaje de visita. Después de vivir en los Estados Unidos por cinco años fue deportado 
al verse involucrado en un accidente automovilístico. Aunque él no era el conductor del vehículo envuelto en el choque, Ramón fue detenido al no poder proporcionar documentos que comprobaran estatus migratorio. A consecuencia de esto, Ramón estuvo en la cárcel por casi dos meses y fue deportado al estado de Coahuila, aunque era de otra parte de México. Ramón comento que el consulado de México le apoyó con la mitad de su viaje. También indicó que el consulado también lo recibió a él y otros inmigrantes dándoles agua, la oportunidad de usar el teléfono, y con un apoyo financiero para pagar por la mitad del boleto de autobús para llegar a su ciudad.

Luis

Luis intentó cruzar la frontera varias veces y al fin pudo llegar a los Estados Unidos. Luis comentó que los primeros seis meses fueron muy difíciles porque no tenía trabajo estable ni un lugar donde quedarse. A veces se quedaba con conocidos y en otras ocasiones dormía en la calle entre cartones o en basureros. Después encontró trabajo y unos paisanos lo invitaron a quedarse en un "trailer park" con ellos. Luis estaba trabajando en un rancho y escuchó en las noticias que había un programa donde podía pedir permiso para trabajar legalmente en los Estados Unidos. Fue con su patrona a las oficinas de inmigración para obtener el permiso y allí es donde fue detenido y después deportado. Luis relató que fue una experiencia difícil y que recibió ayuda psicológica por la depresión que sufrió.

Alberto

Alberto vivió en los Estados Unidos por unos tres o cuatro meses. Se mudó para los Estados Unidos porque se le había ofrecido un trabajo y había perdido su trabajo en México. Durante su estancia en este país, Alberto trabajó como administrador de un bar. Alberto cruzó a los Estados Unidos con el uso de su pasaporte local. Su deportación fue provocada después de ser denunciado por un compañero de trabajo. Alberto fue detenido por una semana y después tuvo que presentarse en la corte al mes de su detención. Alberto recibió una multa de $\$ 5000$ dólares por no tener documentación. Alberto escogió la salida voluntaria y le dieron dos meses para salir del país. Alberto indicó que cuando fue detenido estaba muy preocupado por su familia y temía que los fueran a encontrar y deportar. Un amigo logró sacar a su familia y llevarlos a México para que estuvieran seguros. Alberto mencionó que para él y su familia fue difícil mudarse de nuevo a México porque ya estaban acostumbrados a vivir en los Estados Unidos.

\section{Héctor}


Héctor migró a los Estados Unidos con una visa y se quedó a vivir con su hermano por más de un año. Héctor fue detenido y después deportado al intentar extender su permiso. Siguiendo las recomendaciones de un agente de la aduana, Héctor se esperó un año después de ser deportado, para intentar renovar su pasaporte. El relató, que además de que su solicitud fue negada, lo mantuvieron encarcelado por una hora y media. Entre dos y tres semanas después de este incidente, él fue deportado nuevamente. Esto ocurrió después de intentar cruzar la frontera nuevamente, esta vez, utilizando los servicios de un coyote. Héctor recalcó que su motivación para cruzar la frontera era llegar a los Estados Unidos y tener un trabajo para ayudar a su familia. Héctor relató sentir coraje y resentimiento por el maltrato que sufrió al intentar cruzar de un modo legal y comentó sentirse que no fue tratado justamente.

Mario

Mario es originario del centro de México y narro que le pagó a un coyote para que lo llevara a una ciudad fronteriza desde Michoacán. Mario pasó cuatro días en la ciudad fronteriza y apenas llegando a los Estados Unidos fue deportado y detenido por tres días. Lo deportan a un estado al norte de México, lugar donde permanece hasta hoy. Mario cuenta que ha sido difícil porque no es de allí. Comento sentirse aislado y triste por no tener a nadie. En comparación a los otros participantes, Mario jamás regresó a su pueblo en su estado natal.

Érica

Érica migró a los Estados Unidos acompañada de uno de sus hijos. Ella tenía otro hijo que vivía en Estados Unidos y el plan de reunirse con él fue lo que la motivo a ella y a su hijo a migrar a los Estados Unidos. Érica intentó cruzar dos veces con la ayuda de un coyote. La primera vez, el intento de cruzar fue fallido y Érica fue deportada junto con su hijo. Érica describió los efectos psicológicos y físicos que vivió durante ese intento. Explico que intentaron cruzar caminando, siguiendo los caminos de el coyote que los dirigía por el desierto. Comento que durante ese viaje una espina de mezquite le había golpeado en el ojo y relato como siguió su camino a pesar del dolor. La segunda vez y después de muchos otros sacrificios, lograron cruzar. Érica comento que por cada vez que intentaron cruzar su hijo pagó entre \$1000 y \$1500 dólares. Después de pasar dos meses en Estados Unidos, Érica decidió regresarse a México. Érica contó que no le gustaba la vida en los Estados Unidos porque siempre estaba encerrada y extrañaba la vida que llevaba en México. Aunque Érica regresó a México pudo regresar a Estados Unidos a 
visitar a su hijo con permiso. Érica compartió que su experiencia con su deportación voluntaria no estuvo mal.

\section{Alejandro}

Alejandro vivió en los Estados Unidos por cuatro años con su familia. La familia, al igual que Alejandro, entro a los Estados Unidos con visa de turista. Alejandro cuenta que él vivía "muy a gusto" y tranquilo con su familia en un pueblito. Sus hijas estaban en la escuela y ya habían aprendido inglés. Él y su familia se mudaron a los Estados Unidos por razones económicas y decidieron intentar construir una vida nueva en un pueblo donde también se encontraban otros familiares. Alejandro comentó que después de haber vivido en los Estados Unidos por un tiempo, él y su familia fueron de visita a México. Alejandro decidió regresar del viaje un poco antes que su familia y lo hizo acompañado de un amigo. De regreso a los Estados Unidos, un policía los detuvo en la carretera y fue ahí que lo detuvieron para después deportarlo a México. Como su familia se había quedado en México, después de la deportación de Alejandro, ellos decidieron reestablecerse en ese país. Alejandro indicó que al ser deportado sintió tristeza porque ya había establecido una vida en los Estados Unidos. También relató lo difícil que fue empezar de nuevo en su país y como fue el tener que de nuevo batallar económicamente. Alejandro ha considerado regresar a los Estados Unidos, sin embargo, indico que lo detiene el miedo de ser encerrado de nuevo y dejar a sus hijas y esposa "desprotegidas". Pilar

Pilar cruzó para los Estados Unidos por razones económicas, y por el sueño de poder estudiar. Solo estuvo en los Estados Unidos por cinco meses. Pilar le pagó a un coyote $\$ 800$ dólares para cruzar. Durante sus cinco meses en los Estados Unidos, Pilar no pudo conseguir trabajo. Su mamá la apoyó económicamente durante esos cinco meses. Justo con ese apoyo pudo rentar un cuarto de hotel, donde vivió durante su tiempo en los Estados Unidos. Pilar cuenta que su vida en los Estados Unidos fue difícil por cuestiones de no saber ingles ni como funcionaban ciertas cosas en un país muy distinto a México. Un día que salió a caminar la policía la detuvo, le pidieron sus documentos y al no tenerlos la regresaron a una ciudad al norte de México. Pilar fue deportada sin traer algo de dinero. Esto la obligó a tener que pedir limosnas en las calles y limpiar vidrios de carros para juntar dinero. Tenía una tía que vivía en esa ciudad con cual se quedó mientras juntaba dinero para regresar a casa. Le tomó 20 días poder juntar suficiente dinero para regresar a su ciudad. 
Felipe migró a los Estados Unidos con la esperanza de tener más oportunidades. Él quería estudiar y trabajar para apoyar a su familia económicamente. Felipe comentó ser de una familia grande y de bajos recursos en donde los niños tenían que trabajar vendiendo chicles o periódicos para que todos tuvieran que comer. Felipe viajo a una ciudad fronteriza donde contrató a un coyote. Allí se quedó por ocho días esperando pasar a los Estados Unidos y tuvo que trabajar vendiendo diferentes cosas para poder cubrir sus gastos. Felipe pagó $\$ 850$ dólares para cruzar a los Estados Unidos utilizando lo que el describió ser una llanta de cámara para cruzar por el río. El coyote lo llevó a una ciudad fronteriza en los Estados Unidos. Esa noche durmió en un carro abandonado. Felipe explicó que había cruzado en tiempo de invierno y estaba lloviendo. Felipe describió lo que fue pasar la noche en ese carro abandonado, sin cobija alguna, y un miedo que no le permitió dormir. A la mañana siguiente, salió a buscar trabajo y es cuando lo paró un agente de la patrulla fronteriza y le pidió sus documentos. Al no tenerlos, Felipe fue detenido. Felipe solamente paso dos días en los Estados Unidos antes de ser deportado.

\section{Magdalena}

Magdalena también es originaria de un estado fronterizo y tiene 49 años. Migro a los Estados Unidos con la esperanza de trabajar y apoyar a su familia económicamente. Magdalena pago \$1500 a un coyote para cruzar la frontera. Ella solo estuvo en los Estados Unidos un mes antes de ser deportada. Al llegar a los Estados Unidos, Magdalena toco puerta por puerta pidiendo empleo. Fue así que llego a casa de la pareja que la contrató como trabajadora doméstica. Magdalena relató como durante el tiempo que trabajo para ellos, no le permitían salir de la casa. Después de exigir sus honorarios, la pareja con la que trabajaba casualmente se ofreció a dejarla salir y llevarla con ellos a un centro comercial. La dejaron en un estacionamiento, donde acordaron verse después de terminar sus compras. Fue ahí en ese estacionamiento donde la patrulla fronteriza la detuvo. Magdalena platicó que la pareja solamente le pago \$50 dólares por trabajar 15-20 días.

\section{Recolección y Análisis de Datos}

Todas las entrevistas se realizaron en una sesión. Debido a la vulnerabilidad de los participantes fue poco probable poder obtener una segunda entrevista ya que en ningún momento se les pidió divulgar su verdadero nombre, número de teléfono, o cualquier otra información que pudiese haber facilitado contacto posterior a la primera entrevista. Considerando que los participantes se encontraban en otro país (México), las entrevistas 
fueron realizadas por teléfono y se llevaron a cabo desde una agencia gubernamental en México. Una coordinadora de la agencia se encargó de facilitar las entrevistas incluyendo coordinar las llamadas entre los participantes y la investigadora principal, entregar la información y compensación a los participantes, y asegurarse de que los participantes tuvieran un espacio privado (en este caso, una oficina) durante la entrevista.

Las entrevistas fueron grabadas y después transcriptas textualmente para facilitar el análisis de la información obtenida. Todos los participantes optaron por completar la entrevista en español, y así mismo fueron provistos con la información pertinente en su idioma preferido. Las transcripciones de las entrevistas fueron revisadas para remover cualquier información que pudiese facilitar la identificación de los participantes. Una vez que las transcripciones fueron revisadas, dos fases de análisis de datos fueron completados: codificación abierta y codificación focalizada (Saldaña, 2016). La fase inicial (codificación abierta) consiste en analizar y reflexionar acerca de los datos e identificar códigos tentativos o provisionales (Saldaña, 2016). Una vez completada la codificación abierta, los códigos identificados fueron analizados a profundidad y se desarrollaron temas o categorías. Durante la segunda fase de análisis, se empleó el método de codificación focalizada. Este método consiste el categorizar los datos aún más basado en compatibilidad temática o conceptual (Saldaña, 2016). Estas últimas categorías fueron utilizadas para capturar las experiencias de los participantes relacionados con su proceso de deportación.

\section{Resultados}

Las transcripciones fueron analizadas y produjeron un sinnúmero de categorías. Sin embargo, para propósitos de este manuscrito, solamente las categorías relacionadas al impacto emocional y psicológico de la deportación fueron incluidas. El análisis de datos reveló la presencia de tres categorías principales: El Trauma de la Deportación, Volver a Empezar, y Las Cicatrices Emocionales. La primera categoría principal, El Trauma de la Deportación, se divide en dos subcategorías: El miedo a lo desconocido y El sentirse vulnerable. La segunda categoría principal, Volver a Empezar, se divide en tres subcategorías: El sentirse fracasado, Adaptarse a una nueva vida, y Los sueños no realizados. La última categoría principal, Las Cicatrices Emocionales se divide en dos subcategorías: Depresión y Tristeza. 


\section{El Trauma de la Deportación}

Esta primera categoría se enfoca en las experiencias de los participantes durante el proceso de la deportación. La mayoría de los participantes expresaron miedo cuando estaban pasando por la experiencia de ser deportados. Los participantes señalaron que uno de los factores que más contribuyó a ese sentimiento fue la falta de comunicación entre los agentes de inmigración estadounidense y las personas durante el proceso de deportación. Muchos participantes relataron desconocer los detalles del proceso, incluyendo por cuánto tiempo iban a estar detenidos, provocando preocupación, miedo, y ansiedad. Algunos participantes compartieron el sentirse "nerviosos", ya que en la mayoría de los casos desconocían sus derechos y que pasaría una vez que fueran deportados a México.

\section{El Miedo a lo Desconocido}

En esta subcategoría, los participantes comparten el miedo que sintieron cuando fueron capturados por la patrulla fronteriza. Gran parte de este miedo estaba relacionado con el desconocer lo que estaba sucediendo, a donde los iban a llevar, y que sucedería una vez que fueran regresados a México. Mario, por ejemplo, relató que fue detenido por tres días sin saber lo que iba pasar. Debido a esta situación, Mario describe que estuvo en un constante estado de "nervios" desde cuando se despertaba hasta la hora de dormir. Mario describe su experiencia de estar detenido:

Entonces entras en shock, te da miedo porque al no dar explicación de lo que está sucediendo ahí y no te dicen cuál va a ser el procedimiento a seguir, te metes en una situación de nervios y en un momento mal porque en México están esperando, con cuanto tiempo ibas, amanecen y anochecen y nada más estás en una situación de nervios y otra vez anochece y está en el lugar ese.

Al igual que Mario, Pilar describe el miedo que sintió al ser detenida ya que desconocía que sucedería como parte de ese proceso. Ella comunicó que tenía metas y planes de desarrollar su vida por medio de la educación ya que estaba estudiando. Pero, al ser detenida ella empiezo a pensar en su vida y los cambios que podrían realizarse. Pilar explicó su experiencia:

Tenía mucho miedo yo, que no me fueran a pasar y que me fueran a dejar en la cárcel y así muchas cosas que ya no iba a poder seguir estudiando y que cosas que yo quería hacer, mis metas y cosas así, que ya no iba a poder cumplirlas y no sé, 
me imaginé muchas cosas, se me hacía que iba a durar en la cárcel bastante tiempo por haber entrado al país ilegalmente...tenía mucho miedo y no podía dormir, que me iban a llevar, ¿qué iba a pasar?, ¿qué iba a ser de mí?

Durante su entrevista, Alberto también comentó acerca del miedo y temor al ser detenido. En su caso, su mayor preocupación era relacionada a lo que pudiera pasarle a su familia que también se encontraba en los Estados Unidos al momento de su detención. Alberto compartió:

Sí, mucho nerviosismo, mucha impotencia, temor, sí, algo de temor, pero, sobre todo impotencia de no poder hacer nada. Porque como le digo, nunca había sido detenido por ninguna causa, y de estar encerrado, me sentía muy impotente de no poder hacer nada, ni por mí ni por mi familia.

Los comentarios de Marcos, Pilar, y Alberto capturan la complejidad de las experiencias de los participantes. Para muchos de los participantes, la ansiedad y el miedo fueron provocados por varias circunstancias. Además de los sentimientos y reacciones asociados con la falta de información, la mayoría de los participantes también describieron el miedo de no saber cómo les cambiaría la vida una vez regresaran a México. En este particular Pilar comentó:

Pues, que te puedo decir, este, tenía mucho miedo y no podía dormir, que me iban a llevar, ¿qué iba a pasar?, ¿qué iba a ser de mí? Y no sabía yo nada, nada, no tenía yo cómo avisarle a nadie, nada, como que... eran muchas emociones encontradas. Tenía mucho miedo que no sabía si estaba en una ciudad diferente y que no sabía las leyes, nada, no sabía qué podía hacer.

A pesar de que muchos de los participantes expresaron miedo al desconocer el proceso de deportación y lo que les estaba ocurriendo, para muchos ese proceso provoco sentimientos de incertidumbre, frustración, y vulnerabilidad.

\section{El Sentirse Vulnerable}

Durante el proceso de deportación, muchos de los participantes sintieron que "no se podría hacer nada", "ni abogar por ellos mismos". Según los participantes, no sabían a donde los iban a llevar o cuánto tiempo estarían en tránsito. Al describir su experiencia al ser detenido, Alejandro explico: "Me sentí muy frustrado y, y me sentía como delincuente. La verdad, así me sentí muy mal, muy vulnerable". Mario relata su experiencia al estar detenido: 
Y nos tuvieron 3 días, digo 3 días y medio aproximadamente, no teníamos derecho de nada, no te dejan hablar con nadie, no hay, por parte de nuestro país no hay nadie que te asesore o que te digan cuánto vas a estar ahí. Yo pedía hablar por teléfono y me decían que no, que no había ese servicio.

La mayoría de los entrevistados comunicaron que los oficiales de inmigración los dejaban en ciudades fronterizas las cuales para algunos no eran sus ciudades de origen. Los participantes comunicaron que luego de ser deportados llegaron a México sin dinero para comprar boleto de camión, comida o hacer una llamada. Sin dinero, recursos o apoyo se limitan las oportunidades de reunificar estas personas con sus familiares colocándolos en una posición vulnerable. Pilar relata su odisea al momento de ser deportada a México: "tuvimos que trabajar ahí en los semáforos pidiendo dinero y todo y ya de allí juntamos para regresarnos a mi pueblo". Para Mario la situación fue más difícil ya que él era del interior de México. Cuando fue deportado lo dejaron en una ciudad fronteriza de Texas sin dinero ni para comprar comida lo que lo forzó a quedarse en esa ciudad. Mario relata: Cuando yo llegué aquí [a la ciudad fronteriza] yo me quedé solo, sin nadie, sin conocer a nadie. Nadie con quien llegar, no tienes ni siquiera con quien ir a hablar, ni platicar, eso es lo difícil de cuando te regresas, ni siquiera te acercan a tu lugar de origen, te dejan libre, libre y volver vuelves, pero tampoco tienes ya ni el contacto para regresar, ni la capacidad para regresar.

Para la mayoría de los participantes el proceso de la deportación fue uno traumático, lleno de ansiedad, miedo e incertidumbre. De acuerdo a las historias de los participantes, estos sentimientos y reacciones fueron más intensos durante el periodo de detención y los momentos iniciales tras ser deportados. Sin embargo, una vez regresaron a México se encuentran con la dura realidad de tener que volver a empezar.

\section{Volver a Empezar}

Esta segunda categoría refleja los sentimientos que los participantes experimentaron una vez regresaron a México. Para muchos, lo más difícil de la experiencia de la deportación fue darse cuenta de que van a tener que comenzar de cero, y que muchos de sus sueños y metas no podrán realizarse. Para algunos de los participantes esta realización provocó el que se sintieran fracasados y para otros sentimientos de coraje, impotencia, y frustración. Finalmente, para algunos, esta experiencia de la deportación implicó una especie de choque cultural y proceso de 
adaptación ya que muchos tenían una vida hecha en los Estados Unidos. Esta segunda categoría principal se divide en tres subcategorías: El sentirse fracasado, Adaptarse a una nueva vida, y Los sueños no realizados.

\section{El Sentirse Fracasado}

Para muchos de los participantes, el sentirse fracasados fue algo que los marco desde el momento en que fueron deportados a México. La mayoría de los participantes describieron las dificultades que experimentaron para conseguir, vivienda, empleo, y obtener una estabilidad económica. En este particular, Luis relata cómo se sintió al tener que regresarse a México:

...me sentía fracasado porque pues no estaba regresando a México de la manera que yo quería regresar; uno se quiere regresar en un buen vehículo, bien vestido, con dinero en la bolsa; y pues llegar así, con la familia, imagínese. Pues sí, sí considera uno que es un fracaso.

Al igual que Luis, Alberto comparte su sentimiento de fracaso ya que al tener que regresarse a México tuvo dificultades consiguiendo empleo. Alberto nos explica:

Pues, sí se siente uno muy mal, porque piensa uno "soy un fracaso". Se supone que iba a tratar de mejorar mi situación y la de mi familia y, al contrario, regresé peor, porque ni tuve trabajo, estuve sin trabajar en lo que tuve que esperar lo de la Corte, y luego regresar y no tener trabajo, pues, es muy frustrante.

\section{Adaptarse a una Nueva Vida}

Para algunos de los participantes, el proceso de volver a empezar fue más complicado, ya que para aquellos que llevaban años viviendo en los Estados Unidos, el choque cultural fue más bien marcado. En este particular, Ramón comenta:

... pues si, como le digo, uno trabaja allá y tiene sus cosas allá así que dejar todo allá es el trastorno más grande pues mis hijos son de allá, nacieron allá, allá esta mi casa y pues esta una vida formada si me entiende y aquí viene uno a empezar otra vez como de nuevo.

Al igual que Ramon, Alejandro ya tenía una vida hecha en los Estados Unidos cuando fue deportado. Alejandro nos relata lo que significó esa experiencia:

Pues más que nada tristeza porque ya estaba empezando a hacer una vida. Pues la tristeza del trabajo, de que inclusive como le dije, compré una casa y pues, las 
cosas materiales, que dejó uno allá, tenía yo un vehículo y muebles y pues, lo poco que pudo uno hacer allá, lo perdió uno todo y pues, la educación para las hijas que iban muy bien en la escuela y hasta ellas pues se pusieron tristes de saber de qué ya no iban a vivir allá. Y es, muy, muy diferente, pues es triste porque ya tenía uno planes de quedarse por allá y todo se viene abajo.

Finalmente, Alberto describe la incertidumbre que sintió al no poder conseguir trabajo y su preocupación relacionada al proceso de adaptarse a vivir nuevamente en México:

Pues, como le digo, eso, la incertidumbre de no tener trabajo, no tener un ingreso para solventar los gastos de mi familia. Volver a adaptarme nuevamente a acá y conseguir un nuevo trabajo.

\section{Los Sueños no Realizados}

Para algunos participantes, el proceso de la deportación implicó dejar a un lado los sueños y metas trazadas cuando emigraron a los Estados Unidos. Muchos comentaron que su mayor motivación al cruzar la frontera, era obtener una estabilidad económica y poder ayudar a sus familiares en México. Sin embargo, al ser deportados, muchos vieron esos sueños desvanecerse y con ellos una gama de sentimientos encontrados. Por ejemplo, al preguntarle qué sintió cuando fue deportado esto fue lo que Felipe compartió:

...pues frustración, tristeza, muchos sentimientos encontrados, de que o perseguía una meta y pues no se me cumplió.

Al igual que Felipe, Héctor relata lo que significó para él, el no poder realizar sus planes:

Pues mire, lo más difícil es, en pequeñas palabras, el no haber logrado el cometido que uno tenía, el sentirme defraudado y yo haberme propuesto una meta y el no poderla cumplir, eso fue lo más feo que yo sentí, haga de cuenta que sentí como si, como si me hubieran hecho un hoyo y me hubieran echado tierra. Eso fue lo que, lo que más sentí yo, una desesperación muy fea.

Finalmente, Magdalena relata como la deportación la impactó negativamente ya que siente que su sacrificio fue en vano y no pudo cumplir su meta de ayudar a sus hijos. Ella comenta:

Pues, mucha tristeza, porque si ni siquiera valió la pena [el sacrificio], porque ni siquiera recuperé lo que invertí para irme. Este, me sentía como que mis hijos iban 
a estar decepcionados de mí, porque ellos me decían que no me fuera, y yo no les hice caso. Yo tenía la meta de ayudarlos [económicamente] y por eso me fui. Al final no les pude cumplir.

Para los participantes, el volver a empezar y rehacer sus vidas luego de la deportación no fue algo fácil. Como se pudo apreciar en las narrativas muchos de ellos experimentaron sentimientos de fracaso que se agudizaron con el sentir que sus metas y planes se habían quedado en el camino. Para algunos, el volver a empezar, implicó un choque cultural y el adaptarse nuevamente al país que habían dejado años atrás. Sin embargo, para algunos participantes el impacto de la deportación, dejó cicatrices profundas que en algunos casos requirió de ayuda profesional para poder superarlas.

\section{Las Cicatrices Emocionales}

Esta categoría refleja el impacto profundo que tuvo la experiencia de la deportación tanto a nivel emocional como psicológico. Esta categoría se divide en dos subcategorías: Depresión y Tristeza. Durante las entrevistas los participantes compartieron no tan solo sus experiencias durante el proceso de la deportación, sino que tuvieron la oportunidad de reflexionar acerca del impacto emocional de esta experiencia. Al preguntarles acerca de cómo se sintieron al ser deportados, la mayoría indicaron sentimientos de tristeza, los cuales generalmente eran acompañados de otros sentimientos tales como frustración, coraje, e impotencia. Sin embargo, varios participantes describieron un impacto más profundo, que para algunos desemboco en un estado de depresión. Muchos de los participantes que describieron sentirse deprimidos, también comentaron que recibieron ayuda psicológica para poder manejar la secuela emocional provocada por la deportación.

\section{Depresión}

La depresión, fue uno de los temas que sobresalió en las entrevistas con los participantes. Diferente al miedo, la ansiedad, y la incertidumbre que usualmente se manifestó durante el periodo de detención y los primeros días después de ser deportados, los sentimientos asociados con la depresión estuvieron presentes a lo largo de toda la entrevista.

Como se había mencionado anteriormente, todos los participantes en el estudio fueron deportados a México, sin embargo, el tiempo que cada uno había pasado en los 
Estados Unidos fue diferente. Algunos participantes tenían vidas establecidas, trabajo, casa y familia, otros apenas habían llegado a los Estados Unidos al momento de ser deportados. Para muchos de los participantes la experiencia ser deportado, implico "perderlo todo" y verse forzado a "construir una nueva vida", como fue el caso de Luis y Ramón. Tanto Luis como Ramón, comunicaron el sentirse “derrumbados" y "desanimados" al tener que reconstruir sus vidas. Ramón usa la palabra "herida" como metáfora para describir el sentimiento que queda después de ser deportado:

Uno trabaja allá y tiene sus cosas allá así que dejar todo allá es lo...es el trastorno más grande pues mis hijos son de allá, nacieron allá, allá está mi casa y pues esta una vida formada si me entiende y aquí viene uno a empezar otra vez como de nuevo...la desesperación... que ya va a cambiar su vida...si, se extraña todo eso porque ya sabe uno que no puede uno volver entonces se tiene uno que adaptar y a vivir con eso, vivir con esa herida.

Luis relata que después de la deportación comenzó a sufrir de baja autoestima y comunica lo difícil que era seguir con su vida y tener motivación. Durante la entrevista, Luis utilizó la palabra "trauma" para describir el impacto que tuvo en su vida el ser deportado. Luis comentó en su entrevista:

Pues frustración, fue tristeza, fue pues muchos sentimientos encontrados, de que yo perseguía una meta y pues no se me cumplió...Pues muy mal, me dio depresión y pues hasta enfermo, estuve en tratamiento con unos conocidos de mi familia que son psicólogos y me estuvieron atendiendo en sesiones y pues era frustración lo que yo sentía por no poder cumplir lo que yo tenía como meta, que no pude hacer a pesar de todos los riesgos.

Luis relata que tuvo que buscar ayuda psicológica después de ser deportado porque al igual que otros participantes la experiencia fue una "traumática". Luis nos compartió su sentir:

Entonces ya... al estar aquí en México, y venir aquí en las condiciones en que vine, pues haga de cuenta que a mí me causó -por así decirlo- algunos traumas, ¿verdad?, porque... Como con baja autoestima en la persona de uno. Que son cosas de las que uno se tiene que reponer, a volver a buscar trabajo, a sentirse... se siente uno mal, ¿me entiende? Entonces batalla uno para desenvolverse, para seguir superándose; batalla uno. De hecho, tuve que, inclusive, recurrir ahí a algunas sesiones psicológicas porque... pues necesitaba... tuve que tener ayudar profesional, porque me deprimía muy a menudo. 
Finalmente, Mario relato como cayó en una depresión profunda al verse solo, sin ninguna fuente de apoyo, y sin posibilidades de regresar a los Estados Unidos. Mario comenta:

No pues te sientes solo, te sientes derrotado y me deprimí mucho porque tu objetivo era cruzar y hacer algo mejor allá y tienes una esperanza estar ahí en el otro lado y al regresarse y al no querer estar ya ahí, porque yo no me quería regresar a mi pueblo, porque no tenía a qué regresarme allá, me hubiera ido peor, me hubiera ido peor que haberme quedado aquí en la frontera es muy triste, tenía una especia de soledad muy fuerte.

\section{Tristeza}

Al igual, que la depresión, muchos de los participantes compartieron su sentimiento de tristeza al ser deportados. En particular, ese sentimiento de tristeza venia acompañado de un sentimiento de pérdida. En la mayoría de los casos, los participantes decidieron irse a los Estados Unidos en busca de una vida mejor, pero las circunstancias no le permitieron realizar sus metas y por ende se sintieron defraudados. Para muchos de los entrevistados, el sentirse defraudados estaba relacionado con el no poder brindarles una vida mejor a sus familiares.

Mario relata la tristeza que sintió al ser deportado. En su caso, la situación fue más complicada ya que el provenía de otra parte de México y no tenía manera de comunicarse con su familia. Mario compartió:

Al principio fue muy difícil, fue muy triste, estaba solo y yo no tenía dinero ni siquiera para hacer una llamada y decirles: 'oigan, estoy bien' si pasé o no pasé o no tener dinero, y hay días en que no tienes ni siquiera con que comer, es muy triste y ahorita gracias a Dios tengo un trabajo ya y mi esposa y mi hijo están aquí, pero al principio sí fue muy difícil.

Al igual que Mario, Alejandro describe el sentimiento de tristeza que lo embargó cuando fue deportado. A diferencia de Mario, Alejandro llevaba tiempo viviendo en los Estados Unidos con su familia lo que dificultó más aun el proceso. Alejandro nos comenta las emociones que le provoca el que sus hijas estén pasando por este proceso:

Como le digo, también siento mucha tristeza porque ellas, las niñas ya iban encaminadas allá en la escuela, llegan para acá y todo muy diferente, allá estaban 
muy bien, aquí batallan por cosas, por falta de recursos, a mí me da tristeza porque yo sí estaba mejor allá.

Finalmente, Pilar habla del sentimiento de tristeza que le provoca recordar toda la experiencia, en particular, por los sentimientos de culpa relacionados a "ser una carga para otros". Pilar nos relata:

Pues es triste recordar todas las cosas que yo viví, porque fueron muy difíciles, estar pidiendo dinero, estar pidiendo prestado, yo por lo menos me fui de México para poder superarme y no estar dependiendo de las demás personas y creo que fue al revés, me tuvieron que estar manteniendo, todos esos días, para poder completar el pasaje, fue muy feo, la verdad.

En resumen, esta última categoría reflejo las cicatrices emocionales provocadas por el proceso de la deportación. Como se pudo apreciar en esta sección, varios participantes describieron los sentimientos de tristeza y en ocasiones, depresión que caracterizaron los días, semanas, y meses después del proceso de deportación. Como reflejan las historias, la experiencia negativa de la deportación tuvo repercusiones emocionales, que en algunos casos llevaron a los participantes a pedir apoyo emocional y psicológico.

\section{Discusión}

\section{El Trauma de la Deportación}

La primera categoría principal, El Trauma de la Deportación, se dividió en dos subcategorías: El miedo a lo desconocido y El sentirse vulnerable. Para la mayoría de los participantes el proceso de la deportación fue uno traumático, lleno de ansiedad, miedo, e incertidumbre. Según los participantes, estos sentimientos fueron más intensos durante el periodo de detención y los momentos iniciales tras ser deportados. Con relación a la primera subcategoría, El miedo a lo desconocido, Mario, Pilar, y Alberto relatan el temor y la incertidumbre que sintieron al no tener una idea clara de lo que estaba ocurriendo durante su detención. Sentimientos que fueron aumentando debido a la falta de comunicación por parte de los agentes de inmigración y las barreras del idioma. Las experiencias de estos participantes fueron congruentes con el argumento de que la deportación es un proceso que, para los afectados, empieza mucho antes de ser removido de un país a otro (Drotbohm \& Hasselberg, 2015). 
La segunda subcategoría, El sentirse vulnerable, refleja el sentimiento de impotencia y vulnerabilidad que los participantes sintieron durante el proceso de la deportación. En este particular, Alejandro, Mario, y Pilar relatan como durante el proceso fueron tratados como criminales, nadie les daba información o los asesoraba, y sintieron que no había nada que pudieran hacer para defenderse. Pilar y Mario también relataron como una vez que fueron deportados a México, sintieron que estaban solos y tuvieron que recurrir a pedir en las calles y buscar trabajo para poder sobrevivir.

Estos hallazgos son similares a los encontrados por Aranda y Vaquera (2011) los cuales discuten las actitudes y prácticas de los agentes de la patrulla fronteriza. Ambas investigaciones concurren en que la falta de información acerca del proceso, y las acciones de muchos de los agentes de inmigración aumenta el sentimiento de incertidumbre, temor, y vulnerabilidad de las personas que han sido detenidas y eventualmente deportadas.

\section{Volver a Empezar}

La segunda categoría principal, Volver a Empezar, se divide en tres subcategorías: El sentirse fracasado, Adaptarse a una nueva vida, y Los sueños no realizados. Esta categoría describe como para muchos de los participantes el proceso de la deportación implico un nuevo comienzo. Para aquellos que no estuvieron mucho tiempo viviendo en los Estados Unidos, este proceso les provocó el sentirse fracasados y reflexionar acerca de los sueños y metas no cumplidas. Sin embargo, para los participantes que ya tenían una vida hecha en los Estados Unidos, este volver a comenzar también implico un periodo de ajuste y choque cultural.

En la primera subcategoría, El sentirse fracasado, Luis y Alberto relatan la frustración que les produjo el ser deportados, en particular, porque no era lo que ellos esperaban. Similar a otras investigaciones (ej., Debry, 2012; Hagan et al., 2010), el sentimiento de fracaso estaba relacionado a no poder regresar con recursos económicos que les permitieran darle a su familia una vida mejor. En la segunda subcategoría, Adaptarse a una nueva vida, Ramón, Alejandro, y Alberto relatan las dificultades relacionadas a adaptarse nuevamente a la vida en México. En particular, los participantes comentaron acera de la diferencia en estilo de vida, las oportunidades de trabajo, y las oportunidades educativas para sus hijos. Finalmente, la tercera subcategoría, Los sueños no realizados, describe la añoranza de los participantes al no poder ver sus metas 
cumplidas. En particular, Felipe, Héctor, y Magdalena relatan como el haber sido deportados les hizo sentir derrotados y que su sacrificio fue en vano, ya que no pudieron cumplir las metas trazadas ni las expectativas que otros, en particular, las de sus familiares. Estos resultados están relacionados con los encontrados por Brabeck et al. (2011) y López (2012) quienes describieron el impacto de la deportación para las familias, en particular las pérdidas económicas y oportunidades tener una vida más tranquila.

\section{Las Cicatrices Emocionales}

La última categoría principal, Las Cicatrices Emocionales se divide en dos subcategorías: Depresión, y Tristeza. Esta última categoría refleja el impacto emocional y psicológico del proceso de deportación. Similar a otras investigaciones que se han enfocado en el impacto emocional del proceso de inmigración, y en particular la deportación (ej., Achotegui, 2009; Aguirre \& Simmers, 2008; APA, 2012; Bojórquez et al., 2015), la mayoría de los participantes indicaron sentimientos de tristeza, los cuales generalmente eran acompañados de otros sentimientos tales como frustración, coraje, e impotencia. Mario, Alejandro, y Pilar describieron la tristeza que sintieron luego de ser deportados, en particular, por las vicisitudes que tuvieron que pasar una vez que llegaron a México. Para algunos como Alejandro, esa tristeza estaba asociada a un sentimiento de decepción, al no poder hacer que su familia se quedara en los Estados Unidos. Sin embargo, para algunos participantes ese impacto fue más profundo y desemboco en un estado de depresión. Ramón, Luis, y Mario describieron sentirse deprimidos una vez fueron deportados a México no tan solo por las experiencias vividas en los Estados Unidos, sino debido a los sentimientos encontrados. Algunos participantes, incluyendo a Luis, comentaron que recibieron ayuda psicológica para poder manejar el impacto emocional provocado por la deportación.

\section{Implicaciones para Profesionales de la Salud Mental}

Como se discutió en el manuscrito, el proceso de deportación es uno complejo (Kanstroom, 2012), traumático (APA, 2012), y en muchos casos emocionalmente doloroso (Bojórquez, et al., 2015). Las historias compartidas por los participantes arrojan luz sobre la experiencia de la deportación y los sentimientos asociados al mismo. En primer lugar, considerando el impacto emocional de estos procesos en la población inmigrante, es de suma importancia desarrollar intervenciones culturalmente relevantes 
que tomen en consideración el contexto histórico, social, y político de su experiencia migratoria y eventual deportación (APA, 2012). Además, tomando en consideración el clima político actual y el aumento de los sentimientos antiinmigrantes, la educación y promoción de justicia social es de suma importancia. Finalmente, debido a la falta de consistencia relacionada con el nivel de apoyo que reciben personas inmigrantes al ser deportados, otra sugerencia sería la creación de programas enfocados en la post deportación. Estos programas podrían ser desarrollados por profesionales de la salud mental incluyendo psicólogos, consejeros, y trabajadores sociales, entre otros, en colaboración con las oficinas consulares. El enfoque de estos programas podría ser el brindar apoyo a personas deportadas con el fin de reestablecerse en sus comunidades, recibir ayuda psicológica, y conectar a estas personas con los recursos disponibles.

\section{Limitaciones e Investigaciones Futuras}

La presente investigación refleja varias limitaciones. En primer lugar, a pesar de haber completado 10 entrevistas, es importante recalcar que los resultados de este estudio describen las experiencias de estos individuos, y, por lo tanto, los hallazgos no deben ser generalizados a otros grupos de inmigrantes que han sido deportados. En segundo lugar, a pesar de que las narrativas recopiladas nos permitieron establecer conexiones con respecto al proceso de deportación y su impacto psicológico, el tener una muestra más amplia habría facilitado una discusión más profunda sobre los factores específicos involucrados en el proceso de la deportación y los factores que influyen en como los inmigrantes manejan estas situaciones a nivel psicológico.

Finalmente, considerando la integración de la investigación futura, se recomienda que la examinación del proceso de deportación no se limite a la perspectiva de la frontera entre los Estados Unidos y México. En ese particular, investigaciones futuras podrían examinar el proceso de deportación en otros grupos de inmigrantes incluyendo ciudadanos de Honduras, Guatemala, y El Salvador entre otros. Mas aún, la experiencia de inmigración también debería ser analizada desde una perspectiva global para así obtener una comprensión más integral del impacto psicológico que tiene el proceso de deportación en diversas poblaciones. 


\section{Referencias}

Achotegui, J. (2009). Migración y salud mental: El síndrome del inmigrante con estrés crónico y múltiple (síndrome de Ulises). Revista Zerbitzuan, 46, 163-171.

Aguirre, A., \& Simmers, J. (2008). Mexican border crossers: The Mexican body in immigration discourse. Social Justice, 35(4), 99-106.

Alvarado, R. (2008). Salud mental en inmigrantes. Revista Chilena de Salud Pública, 12(1), 37-41.

American Psychological Association, Presidential Task Force on Immigration. (2012). Crossroads: The psychology of immigration in the new century. Washington, DC: Author.

Aranda, E., \& Vaquera, E. (2011). Unwelcomed immigrants: Experiences with immigration officials and attachment to the United States. Journal of Contemporary Criminal Justice, 27(3), 299-321.

Asakura, H., \& Torres Falcón, M. (2013). Migración femenina centroamericana y violencia de género: Pesadilla sin límites en Zona Franca. Revista del Centro de Estudios Interdisciplinario sobre Mujeres, 21(22), 75-86.

Bojórquez, I., Aguilera, R. M., Ramírez, J., Cerecero, D., \& Mejía, S. (2015). Common mental disorders at the time of deportation: A survey at the Mexico-United States border. Journal of Immigrant and Minority Health, 17(6), 1732-1738.

Brabeck, K. M., Lykes, M. B., \& Hunter, C. (2014). The psychosocial impact of detention and deportation on U.S. migrant children and families. American Journal of Orthopsychiatry, 84(5), 496-505.

Brotherton, D.C., \& Barrios, L. (2011). Banished to the homeland: Dominican deportees and their stories of exile. Columbia University Press.

Casas, M. (2014). Caution: Immigration can be harmful to your mental health. Latino/a Psychology Today, 10(1), 6-9.

Creswell, J. W. (2013). Qualitative inquiry \& Research design: Choosing among five approaches (3rd ed.). SAGE.

Dreby, J. (2012). The burden of deportation on children in Mexican immigrant families. Journal of Marriage and Family, 74(4), 829-845.

Drotbohm, H., \& Hasselberg, I. (2015). Introduction to deportation, anxiety, and justice: New ethnographic perspectives. Journal of Ethnic and Migration Studies, 41(4), 551-562.

Hagan, J.M., Castro, B., \& Rodríguez, N. (2010). The effects of U.S. deportation policies on immigrant families and communities: Cross-border perspectives. Globalization, Families, and the State, 88(5), 1799-1824.

Hernández, J. (2010). Contemporary deportation raids and historical memory: Mexican expulsions in the nineteenth century. Journal of Chicano Studies, 35(2), 115-142.

Hipólito-Delgado, C., \& Mann, J. (2012). Illuminating the shadows: Sociopolitical and counseling needs of undocumented Mexican immigrants. Interamerican Journal of Psychology, 46(3), 395-402.

Kanstroom, D. (2012). Aftermath: Deportation law and the new American diaspora. Oxford University Press.

Kirmayer, L. J., Narasiah, L., Muñoz, M., Rashid, M., Ryder, A. G., Guzder, J., Hassan, G., Rousseau, C., \& Pottie, K. (2011). Common mental health problems in immigrants and refugees: General approach in primary care. Canadian Medical Association Journal, 183(2), 959-967.

López, A. (2012). Adjustment to spousal deportation: Exploring the experiences of Mexican immigrant women [Doctoral dissertation, The University of Texas at San 
Antonio]. ProQuest Dissertations and Theses, 257. http://search.proquest.com/docview/1095103013?accountid=12810. (1095103013).

Menjívar, C., \& Abrego, L. J. (2012). Legal violence: Immigration law and the lives of Central American immigrants. American Journal of Sociology, 115(5), 13801421.

Saldaña, J. (2016). The coding manual for qualitative researchers (3rd ed.). SAGE.

Torres, H. L., O’Conor, A., Mejía, C., Camacho, Y., \& Long, A. (2011). The American dream: Racism towards Latino/as in the U.S. and the experience of trauma symptoms. Revista Interamericana de Psicología/Interamerican Journal of Psychology, 45(3), 363-368.

U.S. Department of Homeland Security. (2017). Executive orders on protecting the homeland. https://www.dhs.gov/executive-orders-protecting-homeland

U.S. Immigration and Customs Enforcement. (2017). Fiscal year 2017 ICE enforcement and removal operations report. https://www.ice.gov/removalstatistics/2017\#tab0 